Essential skills and knowledge for troubleshooting e-resources access issues in a webscale discovery environment

\begin{abstract}
Electronic resource access troubleshooting is familiar work in most libraries. But the added complexity introduced when a library implements a web-scale discovery service creates a strong need for well-organized, rigorous training to enable troubleshooting staff to provide the best service possible. This article outlines strategies, tools, and a basic curriculum that librarians can use to both refine their own troubleshooting skills, and systematically introduce those skills to others.
\end{abstract}

Keywords: Electronic resources, Access problems, Troubleshooting, Training

\title{
Authors:
}

Sunshine Carter, Electronic Resources Librarian, University of Minnesota Libraries,170 Wilson Library, Minneapolis, MN, 55455. Email: scarter@umn.edu

Stacie Traill, Metadata Analyst, University of Minnesota Libraries, 160 Wilson Library, Minneapolis, MN, 55455. Email: trail001@umn.edu

This is an electronic version of an article published in Journal of Electronic Resources Librarianship 29(1), 2017, p. 1-15; http://dx.doi.org/10.1080/1941126X.2017.1270096 Journal of Electronic Resources Librarianship is available online at: http://www.tandfonline.com/toc/wacq20/current. 
This is an electronic version of an article published in Journal of Electronic Resources Librarianship 29(1): 2017, p. 1-15; http://dx.doi.org/10.1080/1941126X.2017.1270096 Journal of Electronic Resources Librarianship is available online at: http://www.tandfonline.com/toc/wacq20/current.

\section{Essential skills and knowledge for troubleshooting e-resources access issues in a web- scale discovery environment}

Web-scale discovery indexes are now a well-established part of many libraries' suites of services and tools. These products promise both extensive and easy-to-use access to a library's online resources. While these massive content databases perform well much of the time, inevitably there are many resources that fail when users attempt to access them. At the same time, depending on how a library configures, positions, and markets its web-scale discovery index, many resources that were previously accessible only via searching in discipline-specific databases may be much more visible and findable. As a result, users may newly encounter and report longstanding access problems that were previously unknown to library staff.

Because the increased visibility reveals access problems both old and new, the implementation of a web-scale discovery tool often causes a marked increase in accessproblem reports. Troubleshooting e-resource access problems has always been complex work, and it is challenging to train staff to become skillful troubleshooters. In a library environment where a web-scale discovery index is in use, the work of troubleshooting is even more complex and challenging. In addition to a likely higher volume of reports, staff must contend with an increasingly elaborate and intermingled set of systems and technologies in order to uncover root causes and successfully resolve access issues.

The complexity of troubleshooting in a web-scale discovery environment emerges from a combination of factors. Discovery indexes evolve quickly, in both scope of content and sophistication. There are a larger number of potential failure points among the variety of interoperating systems, and mismatched or inaccurate descriptive and holdings metadata can 
cause misrepresented availability and failed linking. Additionally, frequent updates to the discovery index and knowledge base combined with a lack of local control over individual records make web-scale discovery tools even more of a moving target than were previous library discovery environments, such as those centered around a traditional OPAC, subject databases, and link resolver.

It is clear that web-scale discovery tools often represent a leap forward for discoverability and accessibility of a library's electronic collections. It is also the case that troubleshooting access problems, a task that was already often very difficult, has become more so. When a web-scale discovery system was first implemented at the University of Minnesota Libraries (UML) in 2013, librarians and staff had not only to learn how e-access functioned in the new environment but also to rethink how troubleshooting took place and who did the work in the face of growing numbers of problem reports and a much higher level of complexity. The need to train more staff to be sophisticated troubleshooters was clear; the next challenge was how to accomplish that. To address this need, the authors honed their own troubleshooting skills, then

embarked on a process to develop effective training for other staff. This article describes the key strategies the authors adopted to achieve this goal: taking advantage of the library's problemtracking system; developing a training outline and curriculum based on that system's data; creating process flowcharts to use for training and job aids; and establishing regular group sessions where staff can work collaboratively to solve real-world access problems.

\section{Literature Review}

Electronic resource access problems, a perennial concern for libraries, continue to receive much attention in the literature (Ashmore, Allee, \& Wood, 2015; Glasser, 2012; Graham \& Hosburgh, 2014; Headlee \& Lahtinen, 2014; Mann, 2015; Pan, Bradbeer, \& Jurries, 2011; Stuart, Varnum, \& Ahronheim, 2015). The tenuous environment of e-resource access issues is well illustrated by article titles such as "Who Ya Gonna Call?" (Davis, Malinowski, Davis, 
Maclver, Currado \& Spagnol , 2012), “Boulevard of Broken Dreams” (Donlan, 2007 ),"Why Can’t Students Get the Sources They Need?" (Mann \& Sutton, 2015), and "Maintaining the Magic of Access" (Samples \& Healy, 2014). Studies investigating linking rates have found error rates ranging from 2\% to nearly 40\% (Collins \& Murray, 2009; Mann, 2015; Trainor \& Price, 2010; Wakimoto, Walker, \& Dabbour, 2006).

\section{Troubleshooting in Libraries}

Maintenance and troubleshooting are widely acknowledged as major components of the e-resources lifecycle (Emery \& Stone, 2013; Jewell, et al., 2004; Pesch, 2009). Two recent surveys set out to investigate the current troubleshooting practices of staff in libraries. Samples and Healy (2014) surveyed Association of Research Libraries (ARL) members ( $n=53)$ in August 2013, and Rathmel, Mobley, Pennington and Chandler (2015) surveyed a variety of libraries $(n=234)$ in October 2013. Their surveys, subsequent results, and conclusions primarily addressed three areas: workflows, staffing, and tracking of troubleshooting. The two surveys found similar and complementary results concerning the current state of troubleshooting, as summarized below.

Workflows to troubleshoot access issues do exist in libraries, and most libraries have at least a loose timeframe for resolving issues. Issues typically enter into the troubleshooting workflow either through, or by some combination of, email, forms, or a trouble-ticketing system; triaging is a popular way of starting the workflow process. Technical services staff handle most troubleshooting tasks and, for the most part, do have direct contact with patrons. Most libraries have one to five troubleshooting staff, even for better-staffed institutions. The top three training needs identified by Rathmel, et al. (2015) include basic troubleshooting, a high-level understanding of e-resources, and advanced troubleshooting. It should be noted that:

[A]t least $85 \%$ of the ARL respondents' libraries have a third-party discovery layer interface to search for and display library holdings to patrons. For electronic resources 
management, this often adds some layers of communication and delay to resolving access problems, as there are other systems in which data might be incorrect (Samples \& Healy, 2014, p. 112).

Many libraries track issues in some fashion using tools such as email, library systems (e.g., ERM or ILS), trouble-ticket systems (e.g., problem-tracking or customer-relationship management (CRM) system), etc. Yet $66 \%$ of responding libraries did not collect statistics on troubleshooting (Rathmel, et al., 2015), while the Samples and Healy study showed that the number of issues reported is often the only statistic that will be reported, even with more complex tracking tools (2014).

In the end, both surveys revealed a need for increased proactive and improved reactive troubleshooting. In fact, Samples and Healy (2014) noted the "current state of electronic resource troubleshooting is almost entirely reactive and often unevenly coordinated," and there is "a need for libraries to develop best practices for troubleshooting electronic resources" (p. 114). With those goals in mind, both surveys suggested taking advantage of established tools, developing workflows, and providing training to both primary troubleshooters and front-line staff who may initially receive problem reports.

\section{Troubleshooting skills and knowledge}

Many authors have attempted to identify the skills and knowledge necessary to work with e-resources. Sutton (2011) evaluated competencies present in 190 job ads (posted 20052009) for electronic resources librarians. She identified 75 broad (e.g., communication, collaboration, flexibility) and specific (e.g., link resolvers, licensing, ERMs) competencies. However, Sutton's compilation included few competencies related to troubleshooting; "ER troubleshooting" appeared in less than $14 \%$ of the job ads, while the somewhat related "analytical, problem solving" competency appeared in over $45 \%$ of the job ads. In 2013, NASIG relied on Sutton's research to create NASIG Core Competencies for Electronic Resources Librarians, in which the group enumerated a broad range of competencies in areas such as the 
e-resources life cycle, technology, research/assessment, and others. NASIG's publication included three competencies that explicitly mention "troubleshooting."

Expanding on the work of Sutton and NASIG, Eric Hartnett (2014) evaluated nonsupervisory job ads for electronic resources librarians posted between 2000 and 2012. Hartnett argued that focusing on the changing trends of core competencies in job posting would provide a more future-facing portrait of the skills necessary to work with e-resources. Hartnett (2014) highlighted a rising trend in competencies related to NASIG's "Competency 2.7 (especially linkresolver software, discovery services, and electronic resources management software (ERMS)" (p. 256).

Mastery of the broad competencies identified by Sutton, NASIG, and Hartnett would provide a strong foundation for anyone troubleshooting e-resource access issues; however, even seasoned librarians found "the complexity of handling electronic resource access problems involved a steep learning curve" (Resnick, 2009, p. 106). Sutton (2011) also evaluated course syllabi $(n=286)$ of courses held between 2005 and 2009 at 19 library schools. Her analysis found that two troubleshooting specific competencies, "analytical, problem solving" and "ER troubleshooting" appeared in only 17 (5.94\%) and 10 (3.50\%) course syllabi, respectively (pp. 100-102). Lawson and Janyck, new librarians in 2014, presented their evaluation of their library science studies program's ability to prepare them for e-resources librarian positions (Lawson, Janyck, \& Erb, 2014). Although singular and specific to Lawson and Janyck's experiences, their programs "did not include either methodology or strategies for troubleshooting e-resources. In fact, the most significant roadblock encountered by the presenters [in their new positions] was the lack of troubleshooting experience" (p. 157).

Some authors directly addressed the specific skills or core competencies necessary for effective troubleshooting. Perkins (2008) stated that "an electronic journal problem understood is a problem half solved" (p. 268). Perkins listed basic causes for e-access issues, along with a list of tools necessary to solve those issues. These include accurate acquisition information, a 
detailed troubleshooting workflow or procedure (covering broad and specific issues), communication guidelines (internal and external), and an inquiring mind. A NASIG 2012 preconference panel session presented strategies for troubleshooting e-access problems (Davis et al., 2012). In addition to Perkins' strategies, Davis et al. (2012) suggested technology tools for staff (e.g., to replicate and report an issue), tracking reported problems, building a solutions knowledge base, understanding authentication and OpenURL linking processes, and creating a single-point-of-contact (e.g., a departmental email) to receive information from vendors, staff, and patrons. Resnick (2009) relied on experience and the data from problem logs $(n=133)$ to identify 12 core competencies for troubleshooting. The 12 competencies fell into the categories of communication, technical knowledge, and resource management.

\section{Growth of Web-Scale Discovery}

Although electronic access issues and the competencies required to troubleshoot them have been frequently addressed in the literature, troubleshooting in a web-scale discovery environment is not well covered as of this writing. Web-scale discovery indexes have received ample attention; complete review of the literature on this topic is beyond the scope of this paper, but a number of recent publications offer insight into what web-scale discovery systems are, how they function, how to evaluate and select one, access problems in web-scale discovery indexes, and what the future of these indexes might be. Breeding (2015) summarized the current state of discovery layers and web-scale discovery indexes, noting that at present, no open-source, web-scale discovery indexes exist. This means libraries choosing to implement a web-scale discovery tool must typically grapple with the closed nature and limited control that often come with vended systems. Deodato (2015) offered a high-level checklist to guide evaluation of web-scale discovery tools as part of an RFP or similar purchasing process. Deodato's list of product requirements touches on many elements that affect access, including richness of metadata, currency of content, and data quality. Stuart et al. (2015) shared results of 
a study of linking failures in the University of Michigan's implementation of Proquest's Summon web-scale discovery service, finding that OpenURL resolution failed $20 \%$ of the time. The authors called for libraries to collaborate and improve the OpenURL standard and implementations of it, but their work also clearly points to a need for effective troubleshooting in web-scale discovery environments as long as the current state of linking in these indexes persists.

\section{University of Minnesota Environment}

The University of Minnesota, Twin Cities is a large public research university with more than 30,000 undergraduate students, more than 16,000 graduate and professional students, and almost 17,000 faculty and staff. The University Libraries (UL) provides access to approximately 91,000 electronic journals (excluding freely available serials), 632,000 electronic books, and 500 subject-specific databases. UL implemented an Ex Libris suite of library management and discovery tools in late 2013: Alma library management system (which includes a central knowledge base and link resolver alongside traditional ILS functions), Primo discovery layer, and Primo Central web-scale discovery index (PCl). The systems are shared with the four other campuses in the University of Minnesota system, and some e-resources are purchased or licensed for multiple campuses in the system.

A library-wide reorganization in 2012 led to the creation of the E-Resource Management (ERM) Unit (within the Acquisitions and E-Resource Management Department), with seven fulltime staff. This unit, led by the Electronic Resources Librarian, has primary responsibility for acquiring, licensing, activating, and troubleshooting e-resources. Staff in the Libraries' Data Management and Access (DMA) department, who manage systems and metadata, also play a role in e-resource access and troubleshooting. Several UL departments, including ERM and DMA, use ServiceNow as an issue-tracking system to track, respond to, and resolve reported issues. 


\section{Tracking and Reporting Access Issues}

The 2013 surveys (Samples \& Healy, 2014; Rathmel et al., 2015) call for an increase and improvement in both proactive and reactive troubleshooting activities. Rathmel et al. (2015) stressed, "[t]he linking mechanism between both approaches is data. The tools that prove better at tracking down and serving good data result in better proactive and reactive decision making" (p. 104). In the web-scale discovery environment, tracking complicated troubleshooting leads to a more sophisticated understanding of both the frequency of various problem types and their levels of complexity.

Instituting a system for formalized problem tracking has several positive impacts:

- It creates a method for systematic data gathering for later analysis of problem categories, workloads, and workflows.

- It helps to identify types of problems that occur either less frequently or that are less memorable to troubleshooting staff.

- It can provide clear insight into new types of problems as they arise.

Finally, and perhaps most importantly, problem tracking helps to ensure that problems are resolved. For problems that cannot be resolved, tracking provides a record of what solutions were tried. This, in turn, creates greater efficiency in a troubleshooting workflow, since staff will not spend time duplicating steps for the same types of unresolvable problems.

\section{Methods for Tracking Reported Access Issues}

Keeping track of reported issues is an important part of troubleshooting e-resources. Libraries look for tracking tools with the ability to "keep track of current problem reports; act as an archive of past issues, which in turn helps with future problems, making collectiondevelopment decisions, and year-end reporting; making communication easier; and assume 
reasonable cost and staff effort" (Rathmel et al., 2015, p. 95). No matter the number of problems reported, issues should be tracked.

The type of tracking system will be determined by the number of troubleshooting staff, budget, and the average number of issues reported yearly. Possible tracking tools include but are not limited to email, shared documents, informal and formal ticketing systems, and other current web applications. Some recent literature highlights various tools used in libraries (Borchert, 2006; Ennis \& Tims, 2012; Erb \& Erb, 2014; Browning, 2015; Finch, 2014; Pan, et al., 2011). Regardless of the tracking system used, a single point of contact for reporting issues is desirable. Single points of contact (e.g., problems@yourinstitution.edu) clarify where to send issues, gather all reported problems together, and allow many users to have access to the reported problems.

UL uses the IT service management system ServiceNow through an institution-wide contract. The institutional contract allows UL to use the system at no additional cost. Multiple library units have a ServiceNow service desk, with several email addresses that provide singlepoint-of-contact depending on the issue topic (metadata, e-access, etc.). Staff receive notices about new, assigned, updated, or resolved tickets related to their assigned service desk. Tickets can be reassigned to other service desks to help address access problems with more than one cause. One less-than-ideal characteristic of this tracking system is the inability to customize issue categories for further analysis (due to configuration at the institutional level).

\section{Evaluating Tracked Data}

Periodically reviewing data on reported issues is critical for revising and improving the workflows of troubleshooting. All tracking systems can provide statistics with a bit of work; the more robust the tracking system, the more nuanced the statistical data available. Browning (2015) offers a methodology for evaluating a small subset of troubleshooting information to reach a broader conclusion. By evaluating the previous twelve months of issues a staff can 
evaluate current workflows and create a troubleshooting FAQ/guide for staff and/or patrons (Bazeley \& Yoose, 2013; Erb \& Erb, 2014; Graham \& Hosburgh, 2014; Pan et al., 2011).

The types of information to track include categories, description, resolution time, assigned staff, reassignments and handoffs. Categories might be created for cause of issue, resource type, vendor/platform, and so on. Six simple error categories were created by Mann (2015) for a proactive troubleshooting test: proxy, source, KB, resolver, target, and ILL; these would be equally useful for reactive troubleshooting. Wright (2015) presented a list of detailed outage types used with the University of Michigan's tracking tool: bundled content, configuration, proxy, violation/breach, holdings, metadata, openURL, scheduled maintenance, target content lacking, target site down, temporary glitch, subscription, and other. Concise descriptions are helpful for searching for similar issues and conveying the main cause of the problem. Having a method to track resolution time may be useful to demonstrate workload as well as complexity. Librarians should take care in making broad conclusions based on resolution time. A long resolution time does not mean the patron's needs were not met in a timely fashion; sometimes a solution is out of the library's hands, and a vendor's priorities are often different than the library's priorities. Understanding the flow of issues is helpful for evaluating workflow improvements or potential areas of collaboration. Many handoffs can signify complexity or a multi-faceted issue; ambiguity in a solution can also be the cause.

\section{Checklist of Essential Skills and Knowledge for Troubleshooting Access Problems}

Teaching other library staff the skills and knowledge needed for effective troubleshooting is important for many reasons. Troubleshooting in a complex web-scale discovery system is a specialized function that can easily fall upon the shoulders of one or a few individuals in an institution. After migrating to a new web-scale discovery environment, the authors observed an increase in the quantity and complexity in the types of access issues reported; it was necessary for the authors to learn these skills themselves. While some of the troubleshooting skills 
necessary to resolve issues remained the same, new skills were required. Without expanding the number of troubleshooting staff, it was challenging to keep pace. Increasing the skills and number of individuals who can contribute to troubleshooting activities increases capacity, builds sustainability, and helps preserve institutional memory for the future.

Consistent and ongoing training helps to empower staff who need or want to troubleshoot more effectively. Additionally, when multiple staff in a single library are tasked with troubleshooting, a consistent approach also benefits users, who will receive more uniform responses to their problem reports. At the University of Minnesota, the authors use many tools and tricks for troubleshooting, but not all staff are aware of these tools or know how to use them effectively. Compiling and widely sharing a list of these tools and tricks is an important task to complete before embarking on a broader training program.

Staff members working to improve their troubleshooting skills come with their own ideas, experiences, and skill sets. A supportive and iterative training process can help each staff member learn at his or her own pace and build on the current knowledge base. Among other benefits, this enables the creation of a tiered service environment where simpler access issues can be assigned to beginners, and more complex access issues can be assigned to advanced troubleshooters.

To develop effective documentation, tools, and training, e-resource librarians need to cultivate a thorough understanding of the broad skills and knowledge staff should have to successfully resolve access issues. A checklist is a simple way to organize the essential concepts staff need to do their jobs effectively. A good checklist also functions as a selfassessment tool and a curriculum outline, helping staff in training understand the broader context of their work and identify goals for individual development. The specific elements of any troubleshooting checklist will differ, depending on the number and type of systems involved in eresource access as well as the specific systems in production at a library. 
At the University of Minnesota, the authors developed a training checklist based on their experiences implementing and troubleshooting Ex Libris's Alma LMS (which includes a link resolver), Primo discovery layer, and Primo Central web-scale discovery index. Some libraries may find that a subset of these checklist topics is sufficient for their discovery environment, while others may find that additional topics are needed. This list attempts to generalize concepts common to e-resource management and troubleshooting across a variety of systems and environments (see Figure 1).

Figure 1. Essential Skills and Knowledge for Troubleshooting Access Problems

\begin{tabular}{|l|}
\hline 1. Overview of discovery and access environment \\
\hline 2. Common points of failure \\
\hline 3. Authentication and authorization \\
\hline 4. OpenURL and link resolvers \\
\hline $\begin{array}{l}\text { 5. Differences and similarities between access for OAffree resources and licensed/paid } \\
\text { resources }\end{array}$ \\
\hline 6. Discovery index content, activations, and linking mechanisms \\
\hline 7. Metadata sources, quality, and impact on access \\
\hline 8. Detailed interaction between link resolver, discovery index, discovery layer, and LMS \\
\hline 9. Distinguishing isolated issues from widespread problems \\
\hline 10. Effective communication with system vendors and content providers \\
\hline
\end{tabular}

The checklist includes broad conceptual areas presented in a logical sequence. Within each area, librarians will want to cover specific subtopics. Appropriate subtopics will vary depending on the library's specific systems and implementation choices, but the discussion of each checklist item below proposes several potential subtopics to serve as either templates or examples. Suggested readings offer an introduction to some of the major checklist areas. Librarians may wish to include additional reading selections from local system documentation when appropriate. 


\section{Overview of Discovery and Access Environment}

The foundation for learning to effectively troubleshoot access problems is a broad overview of the library's discovery and access environment. This overview provides essential context for the more detailed discussions of specific systems, functions, and interactions that make up the rest of the training curriculum. The overview should cover topics such as:

- Which systems are part of the library's discovery and access environment

- What connections exist among those systems

- Which types of data are handled by each system

- Who in the library is responsible for maintaining the various systems

A simplified system-context diagram is an excellent tool for the visual presentation of this information. A system-context diagram shows the library's discovery and access systems and the relationships among them. The point of the diagram is not to provide detailed information on system interactions but rather to provide an easy way to help staff envision where access problems might occur as the various systems work together. For example, the University of Minnesota's system-context diagram (Figure 2) depicts a simplified version of the systems involved in discovery, metadata management, link resolving, and authentication/authorization. 
Figure 2. University of Minnesota System Context Diagram

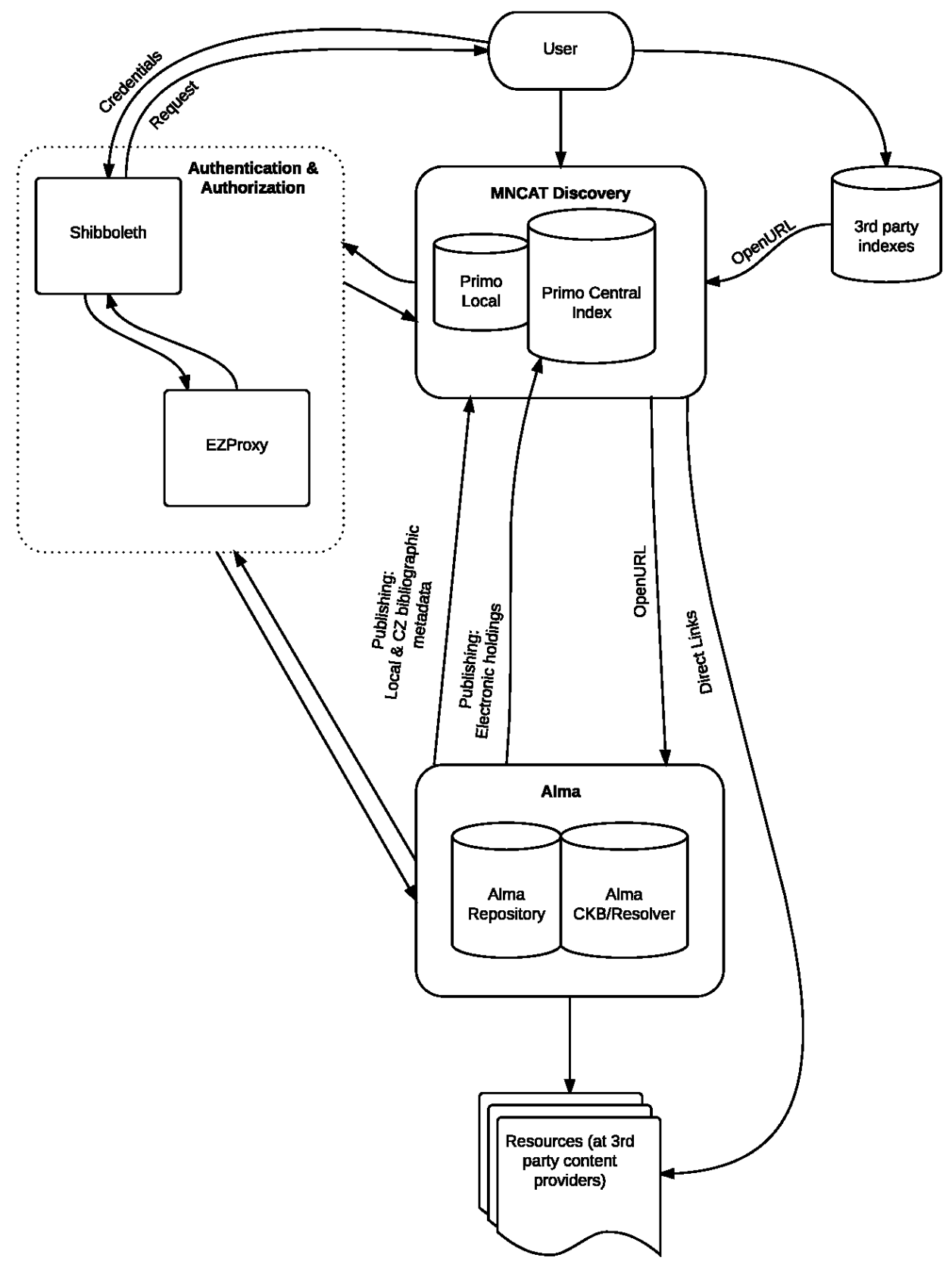


A suggested reading for this topic area that effectively introduces web-scale discovery systems and their content is Vaughn's 2011 report "Web Scale Discovery: What and Why?"

\section{Common Points of Failure}

Once staff have been introduced to the various components of the library's discovery ecosystem, the natural next step is to address common points of failure that cause access problems. Depending on the systems in use, common failure points might include:

- User authentication/authorization (e.g. IP, Shibboleth, proxy)

- Revoked access to vendor content

- Failed direct links to resources

- Failed OpenURL resolution

- Inaccurate knowledge base information (coverage, thresholds, and so on.)

- Library holdings incorrectly reported to discovery system

- Vendor system problems

- Acquisitions failure (e.g. subscription lapse, non-activation, subscription agent error)

The goal at this stage of training is to give staff a high-level summary of access-failure causes to cultivate understanding of the wide variety of potential problems. The details of how to deal with each type of failure should be addressed later in the training curriculum. The suggested reading for this topic area is Perkins's 2008 article "Solving Electronic Journal Problems Effectively: A Short Guide."

\section{Authentication and Authorization}

Because so many access problems for content that is not freely available occur when users affiliated with the institution or library cannot be properly authenticated, it is critical that staff understand this topic well. The authentication and authorization landscape can be complex, and staff should be acquainted with these topics:

- Who the institution's authorized users are 
- Which users can access library resources remotely

- How off-campus access to library resources is offered

- Special allowances/restrictions of access: VPN, special credentials (e.g., flags)

- Campus controlled IPs, including special locations (e.g., off-site facility)

- The impact of IP addresses and IP ranges on access

- Designated library tool server IPs (e.g., proxy, metasearch)

- Resources that don't allow for IP authentication

- Which resources should be proxied (e.g., are free/open access resources proxied?)

- How to verify/update IP ranges with vendors

- How to verify IP addresses of patrons/users experiencing issues

- How proxying works (including specific institutional configuration choices)

\section{OpenURL and Link Resolvers}

The OpenURL standard [National Information Standards Organization, 2010] specifies how to construct context-sensitive URLs that rely on a variety of metadata elements about a particular resource (e.g., article, chapter, document) to accurately link across systems. When received and parsed by a link resolver, OpenURLs can take a user from an abstract in one database to the full-text article in another location. Because link resolvers (and therefore OpenURL) are critical parts of most library discovery and access environments, this topic should be covered in some depth. Major concepts to introduce include:

- Definition of OpenURL

- How and where are OpenURLs generated

- What the link resolver is and how it works

- The path an OpenURL takes through the system(s)

Once staff have a solid understanding of these concepts, they will be ready to learn specific strategies for troubleshooting OpenURL and link-resolver issues. The key to 
troubleshooting OpenURL failures is determining where specifically the problem is occurring. Topics of discussion to advance staff in their abilities include:

- How insufficient or incomplete metadata affect the resolution of an OpenURL.

- How the settings and parsers of the link resolver affect the resolution of an OpenURL.

- How the handling of inbound OpenURLs affects resolution of an OpenURL.

- How special metadata elements affect OpenURLs (e.g. DOI, PMID, etc.).

- How OpenURL linking is set up at vendor platforms.

Many publications can serve as effective suggested readings on the general topic of OpenURL and link resolvers. Two excellent articles are Ferguson and Grogg's (2004) “OpenURL Link Resolvers" and Pesch's (2012) "Improving OpenURL Linking."

\section{Differences and Similarities between Access for OA/Free Resources and Licensed/Paid Resources}

Staff should understand how provision of access differs between open access/free resources and licensed e-resources. The key competency for staff is the ability to quickly identify OA and free content, because authentication and user institutional affiliation can often be immediately eliminated as potential causes of an access problem for openly available content. Staff should know:

- What Open Access means

- How to identify OA/free collections in the discovery layer

- How to identify OA/free collections in the link resolver KB

- How to deal with collections that include both free/open and restricted access content

- Institutional policy on activating/making available OA/free content

The suggested reading to introduce the concept of Open Access is the first chapter of Peter Suber's 2012 monograph Essential Knowledge: Open Access.

\section{Discovery Index Content, Activations, and Linking Mechanisms}


The basic organization and management of the discovery index is another piece of essential knowledge for troubleshooting. For staff who may already be familiar with the linkresolver knowledge base, it is important to clarify the differences between the discovery-layer and the link-resolver knowledge bases. Topics to cover in this category include:

- Similarities and differences between the discovery-system knowledge base and the linkresolver knowledge base

- Characteristics of discovery-index collections (Does linking occur via OpenURL or a direct link to the resource? Is the collection open for searching regardless of subscription? Which collections are freely available? What kinds of content are available in various collections, and how does that affect activation choices?)

- Timing of content availability in the discovery layer once activated (Is there a delay? If so, how long is it?)

The suggested reading for this topic area is chapter 4 of Marshall Breeding's 2015 white paper The Future of Library Resource Discovery.

\section{Metadata Sources, Quality, and Impact on Access}

Once staff have learned about the structure and content of OpenURLs and the content of the discovery index and knowledge base, it is time to delve into issues surrounding metadata. Because metadata is critical not only to discovery, but also to the success of content delivery via OpenURL, staff should understand how metadata sources and quality can affect access. Potential topics include:

- Metadata sources (library catalog, link resolver KB, discovery index, institutional repository, and so on)

- Metadata elements that may play a role in access (e.g., how OpenURLs are built from metadata elements)

- How to find and compare citations in provider databases with the discovery layer 
Suggested reading for this topic area is Calarco, Conrad, Kessler, \& Vandenburg's article "Metadata Challenges in Library Discovery Systems" (2014).

\section{Detailed Interaction between Link Resolver, Discovery Index, Discovery Layer, and LMS}

The discovery system's constant state of flux means that staff must have a solid understanding of the processes that control the availability of its content and synchronization with library holdings. Without this knowledge, quick and accurate identification of a problem's root cause is difficult. This area is a logical expansion upon the first checklist item, the overview of the discovery and access environment. At this point, staff should have enough background and technical competence to benefit from a more detailed view, possibly including the following topics:

- Which resources are displayed in search results (local vs. remote? full text only?)

- How library holdings are synchronized between the LMS, link resolver, and the discovery layer

- Timing/scheduling of involved processes

- How to check for process failures that may affect access

\section{Distinguishing Isolated Issues from Widespread Problems}

Sometimes troubleshooting staff will receive several similar reports within a brief time, making it obvious that there is a potentially widespread common cause. But when problem reports trickle in over days or weeks, it can be difficult to see a pattern. Staff should learn some strategies to help identify widespread problems after an initial report, such as:

- Checking more than one resource in a collection or from a particular provider

- Checking access from various points of entry (discovery layer, provider index, Google Scholar)

- Checking unrelated resources last processed/changed on the same day

\section{Effective Communication with System Vendors and Content Providers}


Because not all access problems can be resolved by library staff, troubleshooting inevitably requires communication with system and content vendors and other partners outside the library. Knowing how to craft effective communications to outside partners can expedite solutions as well as help build productive relationships. Some of the skills staff should have to communicate effectively include:

- How to craft a concise yet adequately detailed description of the problem

- Details to supply in problem tickets for vendors/providers (e.g., are there local specifics, such as implementation choices or local customizations, that the vendor needs to know about?)

- How to document steps already taken (both internally, for the reference of other staff, and externally, for vendors/providers)

\section{Approaches and Methods for Documentation and Training}

The baseline skills and knowledge described in the previous section are the central component of any staff training program for effective access troubleshooting. But once staff have acquired a basic understanding of the components of the library's discovery and access systems and how they interact, the more challenging task of solving genuine access problems must be addressed.

Process flowcharting is an approach to training and documentation which is especially well-suited to troubleshooting access problems in library discovery and link resolver tools. Because many access problems can be resolved by applying a methodical series of questions and tests, flowcharts are an excellent vehicle for documenting those processes. Flowcharts are also useful for training, because they give a glanceable, high-level overview of a problemsolving process. Once training is finished, flowcharts can be much more useful as job aids than, for example, a text document with numbered steps, because they are "scannable," offering visual cues that help the troubleshooter to find a specific starting point easily and quickly. 
Preparing process flowcharts can be both challenging and tedious, but it is also an excellent way to think through how troubleshooting processes can be systematized, and thus more easily and consistently applied by multiple staff members. Flowcharting can also help to identify situations where higher-level intervention or referral is needed, something which is especially useful in a multi-tiered support environment. Efficiency is increased both for staff doing initial triage, because the points at which they escalate a problem are clearly defined, and for staff who resolve the most complex problems, because they will not receive problems that could be solved by triage staff.

Many resources are available that describe how to create effective process flowcharts (American Society for Quality, 2015; Laughlin, Shockley \& Wilson, 2003). At a basic level, the essential steps are to categorize access problems into broad types, then document the specific steps a staff member should take in attempting to resolve each type of problem. Once this is done, it is straightforward to identify the decision points which will provide the basic structure of each flowchart.

Two flowcharts to be used in tandem for the resolution of a user-reported access problem illustrate the process. In this example, the user reports that they are unable to access a particular article, but library staff are unable to reproduce the failure. Figure 3 directs the troubleshooter to a detailed flowchart to address the specific problem, shown in Figure 4. 
Figure 3. Troubleshooting: Initial Problem Diagnosis

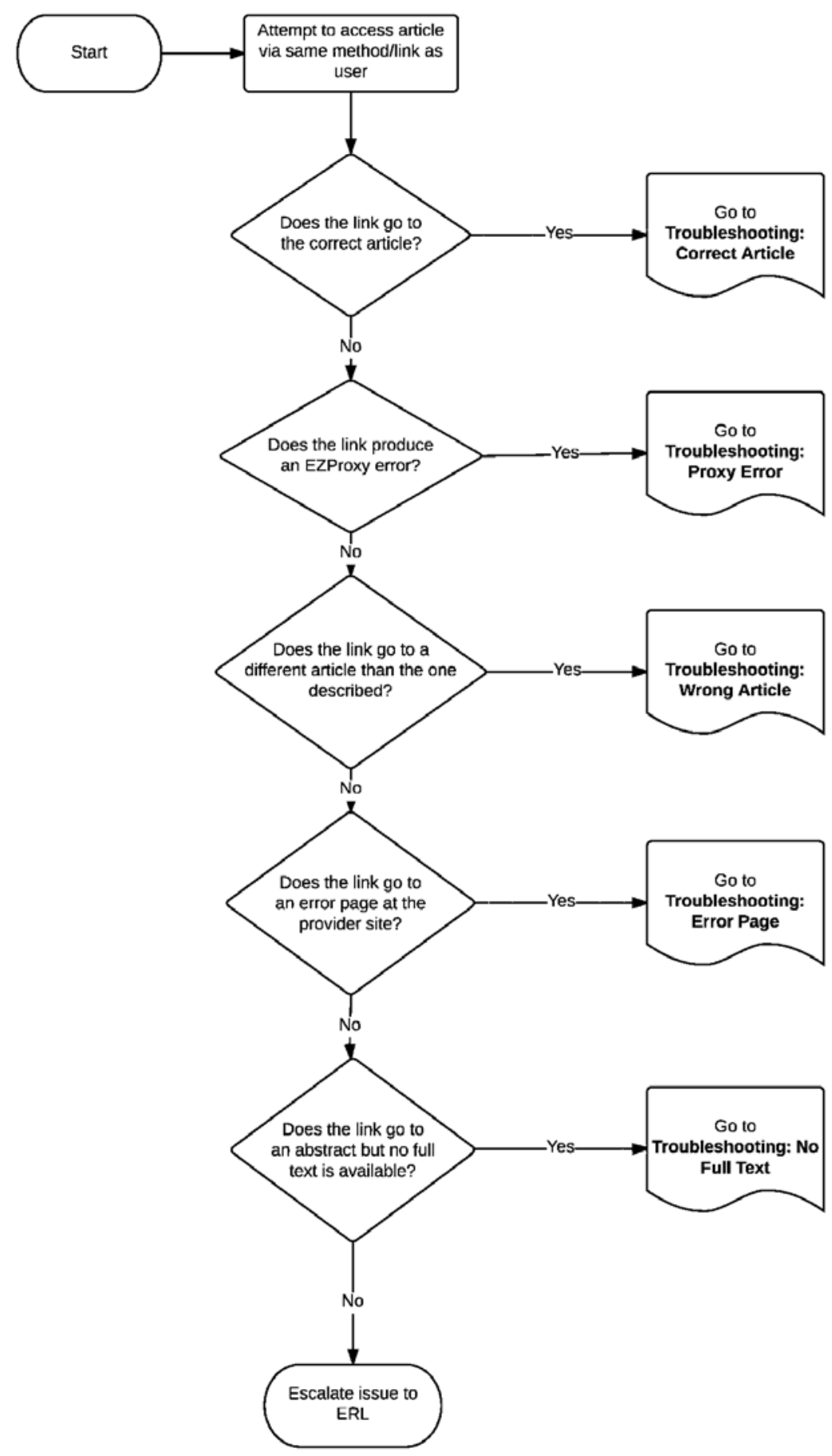


Figure 4. Troubleshooting: Correct Article

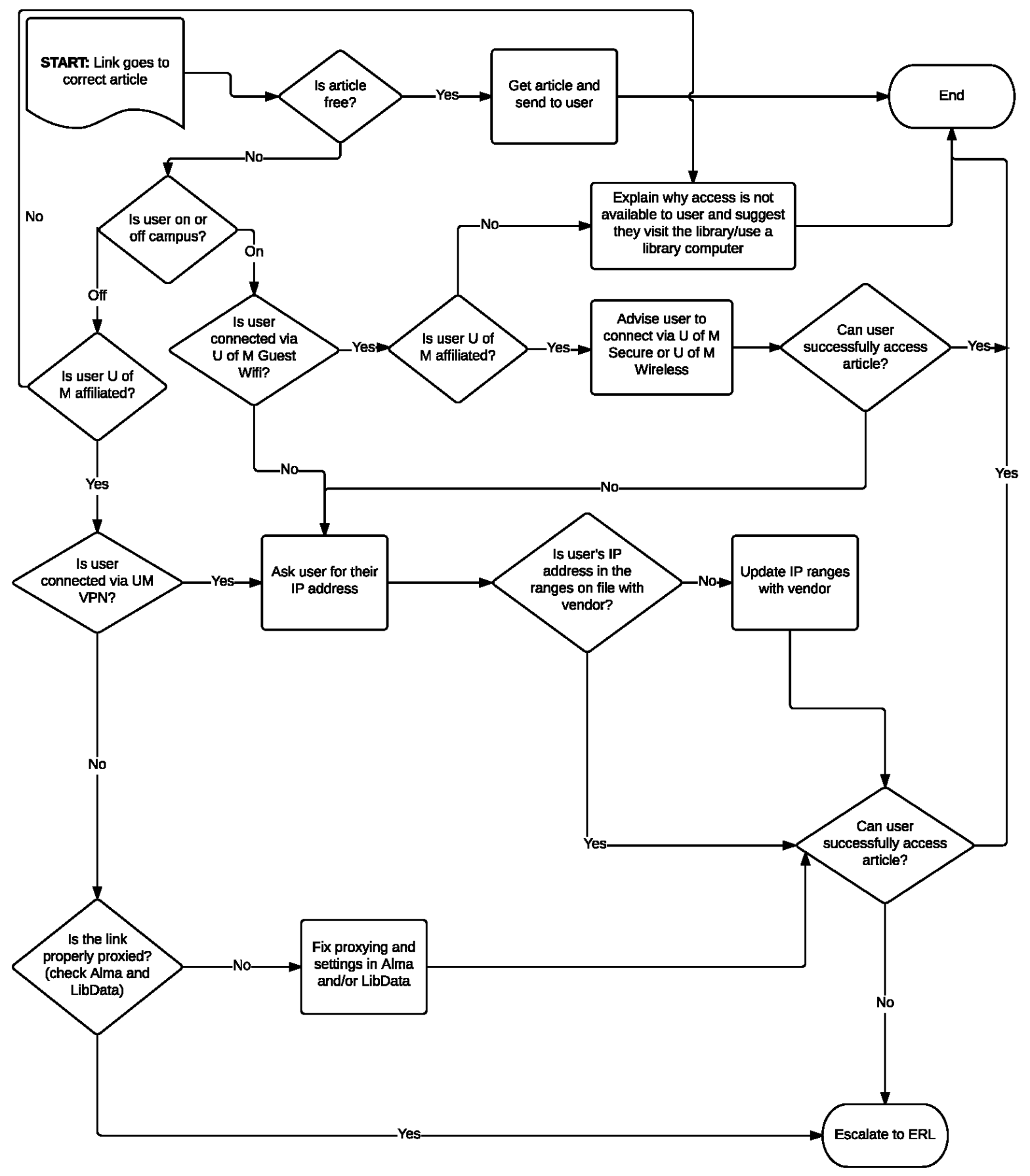


While flowcharts are very useful tools, all but the simplest flowcharts should be complemented by documents outlining specific steps through a process in prose. Textual documentation offers a way to expand on various steps and decision points in a process, and may also work better as training tools for some staff depending on individual learning styles and preferences. Documentation can provide detailed explanations for why certain steps are taken at various points in a troubleshooting process, something which is usually not possible via the brief textual labels for flowchart symbols. Documentation can also define unfamiliar terms. For a flowchart like the one in Figure 3 above, in addition to the detailed steps of the process, the accompanying textual documentation might include a reminder of what VPN is, clarification on the specific escalation path for this type of problem, and links to related procedures or processes cited in the flowchart (if they are documented), such as how to update IP ranges with vendors.

At the University of Minnesota, the authors have increased workflowing activities to realize the benefits of the process. While time consuming, creating workflows for tasks and decision-making processes has provided opportunities for rich discussions about processes, procedures, and policies while elucidating gaps, bottlenecks, and inconsistencies. Creation of workflows of any type also provides a partial answer to the crucial and perennial dilemma of how to maintain institutional memory in the face of retirements, turnover, and other transitions.

Once flowcharts and documentation are in place, in-person training should occur. While the traditional, formalized classroom or online training modules are an essential starting point for staff members new to the work, the complexity and variety of e-resource access problems make it difficult to cover every possibility in formal training. A more effective approach for ongoing training is to hold hands-on troubleshooting sessions, where staff work through real userreported problems together. These sessions will help staff understand how an experienced troubleshooter steps through a series of evaluations and decisions to arrive at likely causes and solutions for specific problems. 
The University of Minnesota's late 2013 migration to new systems caught staff unprepared for the elements of troubleshooting in a complex environment; there was no planned troubleshooting curriculum nor did librarians have a good understanding of the types of issues they would experience. The e-resource management unit now holds regular hands-on troubleshooting sessions. Now that troubleshooting workflows are finalized and a curriculum outline is in place, the authors are in the process of providing formal training for all staff responsible for troubleshooting access issues.

\section{Conclusion and Future Directions}

Troubleshooting access for e-resources is familiar territory in most libraries. Despite this, staff training for troubleshooting is not always clearly outlined or well-documented. Combined with the added complexity introduced when a library implements a web-scale discovery service, the result is an environment that demands both careful problem tracking and well-organized ongoing training to enable troubleshooting staff to provide the best service possible. By adopting the strategies described above, librarians will be able to refine their own troubleshooting skills while systematically introducing those skills to others. Doing so has a number of clear benefits. In addition to faster and more efficient problem resolution resulting in increased user satisfaction, a successful troubleshooting training program also demystifies the workings of the discovery system and empowers library staff with a much better understanding of the tools they and their users work with every day. Finally, a training program helps ensure continuity in the face of staff departures and retirements, allowing new staff to more quickly and effectively master the complexities of their library's discovery environment.

While the strategies and tools discussed in this article represent progress toward the overall goal of improving user access to e-resources, they are primarily reactive to reported problems rather than proactive in finding and solving problems before users encounter them. Although many libraries have tools and procedures in place to find some access problems 
before users do, the authors see a clear need for a comprehensive, generalizable suite of tools, strategies, and processes for proactive troubleshooting, as called for by Samples and Healy (2014) and Rathmel et al. (2015). The authors also echo the needs stated by Stuart et al. (2015) for improvements to OpenURL as well as exploration of open and standardized alternatives to it for linking across multiple providers and databases. NISO's Open Discovery Initiative (ODI), with participants from both libraries and discovery-service providers, is a promising move toward greater openness and standardization that the authors hope will lead to both more transparent systems and fewer access failures (NISO, 2014). But no matter how library discovery systems and electronic access evolve in the coming years, building solid high-level troubleshooting skills among staff will be a vital component in improving library user experiences. 


\section{References}

American Society for Quality (2015). What is a process flowchart? Retrieved from

http://asq.org/learn-about-quality/process-analysis-tools/overview/flowchart.html

Ashmore, B., Allee, E., \& Wood, R. (2015). Identifying and troubleshooting link-resolution issues with ILL data. Serials Review, 41(1), 23-29.

Bazeley, J. W., \& Yoose, B. (2013). Technical services transparency: Using a LibGuide to expose the mysteries of technical services.(Notes on Operations). Library Resources \& Technical Services, 57(2), 118.

Borchert, C. A. (2006). Untangling the jungle of e-journal access issues using CRM software. Library Collections, Acquisitions, and Technical Services, 30(3-4), 224-237.

Breeding, M. (2015). The future of library resource discovery: a white paper commissioned by the NISO Discovery to Delivery (D2D) Topic Committee. Baltimore, MD: NISO. Retrieved from http://www.niso.org/apps/group_public/download.php/14487/future_library_resource_discovery. pdf

Browning, S. (2015). Data, data, everywhere, nor any time to think: DIY analysis of e-resource access problems. Journal of Electronic Resources Librarianship, 27(1), 26-34.

Calarco, P., Conrad, L., Kessler, R. \& Vandenburg, M. (2014) "Metadata Challenges in Library Discovery Systems." Proceedings of the Charleston Library Conference, 533-540.

Collins, M., \& Murray, W. T. (2009). SEESAU: University of Georgia's electronic journal verification system. Serials Review, 35(2), 80-87.

Davis, S., Malinowski, T., Davis, E., Maclver, D., Currado, T., \& Spagnolo, L. (2012). Who ya gonna call? Troubleshooting strategies for e-resources access problems. Serials Librarian, 62(1-4), 24-32.

Deodato, J. (2015). Evaluating web-scale discovery: A step-by-step guide. Information Technology and Libraries, 34(2), 19-75. 
Donlan, R. (2007). Boulevard of broken links: Keeping users connected to e-journal content. Reference Librarian, 48(1), 99-104.

Emery, J., \& Stone, G. (2013). Ongoing evaluation and access. Library Technology Reports, 49(2), 26-29.

Ennis, L. A., \& Tims, R. S. (2012). Help central: Creating a help desk \& knowledge portal in SharePoint. Computers in Libraries, 32(2), 6-10.

Erb, R. A., \& Erb, B. (2014). Leveraging the Libguides platform for electronic resources access assistance. Journal of Electronic Resources Librarianship, 26(3), 170-189.

Ferguson, C. L., \& Grogg J. E (2004). OpenURL Link Resolvers. Computers in Libraries, 24(9), (October 2004), 17-24.

Finch, M. (2014). Using Zapier with Trello for electronic resources troubleshooting workflow. Code4Lib Journal, (26), 1-1.

Glasser, S. (2012). Broken links and failed access. Library Resources \& Technical Services, 56(1), 14-23.

Graham, T., \& Hosburgh, N. (2014). A user-centered approach to addressing issues of discoverability and access. Serials Librarian, 67(1), 48-51.

Hartnett, E. (2014). NASIG's core competencies for electronic resources librarians revisited: An analysis of job advertisement trends, 2000-2012. The Journal of Academic Librarianship, 40(34), 247-258.

Headlee, P. A. \& Lahtinen, S. C. (2014). Callisto. Journal of the Medical Library Association, 102(4), 305-306.

Jewell,T. D., Anderson, I., Chandler, A., Farb, S. E., Parker, K., Riggio, A., \& Robertson, N. D. M. (2004). Electronic resource management. The report of the DLF initiative. https://old.diglib.org/pubs/dlf102/

Laughlin, S., Shockley, D., \& Wilson. R. (2003). The library's continuous improvement fieldbook. Chicago, IL: ALA Publications. 
Lawson, E., Janyk, R., \& Erb, R. A. (2014). Getting to the core of the matter: Competencies for new e-resources librarians. Serials Librarian, 66(1-4), 153-160.

Mann, S. (2015). Electronic resource availability studies: An effective way to discover access errors. Evidence Based Library \& Information Practice, 10(3), 30-49.

Mann, S., \& Sutton, S. (2015). Why can't students get the sources they need? Results from a real electronic resources availability study. Serials Librarian, 68(1-4), 180-190.

NASIG. (2013). NASIG core competencies for electronic resources librarians. West Seneca, NY: NASIG. Retrieved from http://www.nasig.org/uploaded files/92/files/CoreComp/CompetenciesforERLibrarians final ver 2013-7-22.pdf

National Information Standards Organization. (2010). The OpenURL framework for context-sensitive services (ANSI/NISO Z39.88-2004 (R2010)). Baltimore, MD: NISO.

National Information Standards Organization. (2014). Open Discovery Initiative: Promoting transparency in discovery (NISO RP-19-2014). Baltimore, MD: NISO.

Pan, D., Bradbeer, G., \& Jurries, E. (2011). From communication to collaboration: Blogging to troubleshoot e-resources. Electronic Library, 29(3), 344-353.

Perkins, J. (2008). Solving Electronic Journal Problems Effectively: A Short Guide. Journal of Electronic Resources in Medical Libraries, 5(3), 267-273.

Pesch, O. (2009, March). ERMS and the e-resource life-cycle. [PowerPoint slides]. Retrieved from http://tinyurl.com/ERLifeCycle

Pesch, O. (2012). Improving OpenURL Linking. The Serials Librarian, 63(2), 135-145.

Rathmel, A., Mobley, L., Pennington, B., \& Chandler, A. (2015). Tools, techniques, and training: Results of an e-resources troubleshooting survey. Journal of Electronic Resources Librarianship, 27(2), 88-107.

Resnick, T. (2009). Core competencies for electronic resource access services. Journal of Electronic Resources in Medical Libraries, 6(2), 101-122. 
Samples, J., \& Healy, C. (2014). Making it look easy: Maintaining the magic of access. Serials Review, 40(2), 105-117.

Stuart, K., Varnum, K. \& Ahronheim, J. (2015). Measuring journal linking success from a discovery service. Information Technology \& Libraries, 34(1), 52-76.

Suber, P. (2012) Essential Knowledge : Open Access. (Cambridge, MA: MIT Press).

Sutton, S. (2011). Identifying core competencies for electronic resources librarians in the twenty-first century library. (Doctoral dissertation). Retrieved from https://repositories.tdl.org/tamucc$\underline{\text { ir/handle/1969.6/33 }}$

Trainor, C., \& Price, J. (2010). Chapter 3: Digging into the data: Exposing the causes of resolver failure. Library Technology Reports, 46(7), 15-26.

Vaughn, J. (2011). "Web Scale Discovery: What and Why?" Library Technology Reports, 2011(1), 5-11.

Wakimoto, J. C., Walker, D. S., \& Dabbour, K. S. (2006). The myths and realities of SFX in academic libraries. The Journal of Academic Librarianship, 32(2), 127-136.

Wright, J. (2015, January). Electronic outages: Who broke it? How long was it broken? We're...tracking that, right? Presentation at the meeting of the American Library Association, Chicago, IL. 